\title{
An evaluation of real-time troposphere estimation based on GNSS
}

\section{precise point positioning}

\author{
Wenwu Ding ${ }^{1,2}$, Felix Norman Teferle ${ }^{1}$, Kamil Kaźmierski ${ }^{3}$, Denis Laurichesse ${ }^{4}$, \\ Yunbin Yuan ${ }^{2}$ \\ 1 Geophysics Laboratory, University of Luxembourg, Luxembourg \\ 2State Key Laboratory of Geodesy and Earth's Dynamics, Wuhan, China \\ 3Institute of Geodesy and Geoinformatics, Wroclaw University of Environmental and \\ Life Sciences, Wroclaw, Poland \\ 4Centre National d'Etudes Spatiales, Toulouse, France \\ Corresponding authors: Wenwu Ding (bindingboy@gmail.com)
}

\section{Key Points:}

- Real-time troposphere estimation based on actual real-time GNSS observation streams

- Analysis of initialization period and accuracy of GNSS troposphere estimates

- Evaluation of the impact of PPP ambiguity resolution on troposphere estimates

\begin{abstract}
It is anticipated that the performance of real-time (RT) GNSS meteorology can be further improved by incorporating observations from multiple Global Navigation Satellite System (GNSS), including GPS, GLONASS, Galileo and BeiDou. In this paper, an operational RT system for extracting zenith troposphere delay (ZTD) using a modified version of the Precise Point Positioning With Integer and Zero-difference Ambiguity Resolution Demonstrator (PPP-wizard) was established. GNSS, including GPS, GLONASS and Galileo, observation streams were processed using RT Precise Point Positioning (PPP) strategy based on RT satellite orbit/clock products from Centre National d'Etudes Spatiales (CNES). A continuous experiment covering 30 days was conducted, in which the RT observation streams of 20 globally distributed stations were processed. The initialization time and accuracy of the RT troposphere results using single/multi-system observations were evaluated. The effect of RT PPP ambiguity resolution was also evaluated. Results revealed that RT troposphere results based on single system observations can both be applied in weather now-casting, in which the GPS-only solution was better than the GLONASS-only solution. The performance can also be improved by applying RT PPP ambiguity resolution and utilizing GNSS observations. Specifically, we noticed that the ambiguity resolution was more effective in improving the accuracy of ZTD, whereas the initialization process can be better accelerated by GNSS observations. Combining all techniques, the RT troposphere results with an average accuracy of about $8 \mathrm{~mm}$ in ZTD can be achieved after an initialization process of approximately 8.5 minutes, which demonstrated superior results for applying GNSS observations and ambiguity resolution for RT meteorological applications.
\end{abstract}




\section{Introduction}

Atmospheric water vapor plays an important role in various weather and climate processes and as the primary greenhouse gas accounts for $60-70 \%$ of the observed atmospheric warming. Hence it attracts much attention from the atmospheric and climate scientific communities. A number of ground-based and ballon-based techniques can be employed to determine atmospheric water vapor, for example, radiosonde [Coster et al., 1996; Niell et al., 2001], water vapor radiometer [Gradinarsky and Elgered, 2000 ; Madhulatha et al., 2013], and Very Long Baseline Interferometry (VLBI) [Coster et al., 1996; Niell et al., 2001; Teke et al., 2011]. The extraction of zenith troposphere delay (ZTD) and precipitable water vapor (PWV) from Global Positioning System (GPS) observations, denominated as GPS meteorology, was initially proposed by Bevis et al (1992). Since then, extensive studies have been conducted in post-processing [Rocken et al., 1993; Dodson et al., 1996; Haase et al., 2001; Bock et al., 2016] and near-real-time (NRT) [Rocken et al., 1997; Gendt et al., 2001; Dousa., 2001a; Van Baelen et al., 2005; Karabatic et al., 2011] to meet the different requirements, e.g., climate monitoring, numerical weather prediction [Gutman and Benjamin., 2001; Guerova et al. 2013]. The accuracy of the PWV results from GNSS is analyzed by comparing with other techniques, mostly radiosonde [Niell et al., 2001; Ning et al., 2012]. The relevant factors affecting the accuracy are also evaluated in detail [Dach and Dietrich., 2000; Dousa., 2001b; Ge et al., 2002]. All these results reveal that the GPS-based PWV results are comparable to other techniques in accuracy and can be effectively applied in weather forecasting and other meteorological applications [De Haan., 2011].

Severe weather events, which cause large economic losses, become a hot research topic [Vedel et al., 2004; Madhulatha et al., 2013]. Now-casting, which describes the current state of the atmosphere and predict how the atmosphere will evolve during the next several hours, is a powerful tool in warning such events [Mass, 2012]. In addition, operational numerical weather prediction (NWP) models have been used as now-casting tools in recent years, and the assimilation of ground based tropospheric results can provide good upper air humidity information. However, compared with NRT, which usually updates the ZTD results every hour, the applications in the monitoring of short-term weather variation and NWP now-casting require more frequently updated ZTD. For example, now-casting models require the availability of troposphere results with latency less than 10 minutes after data collection [Guerova et al. 2013]. Thus, the real-time (RT) extraction of ZTDs has attracted much attention from the GNSS meteorological community. In terms of the data processing strategy, Precise Point Positioning (PPP) [Zumberge et al., 1997] has become feasible aided by precise satellite orbit/clock products, which can be computed from network data processing with a relatively sparse network. It is close to network solution in accuracy, but more flexible since the observation data of each station is processed separately. PPP ambiguity resolution can also be obtained by several methods to further improve the performance [Ge et al., 2008; Laurichesse et al., 2010; Geng et al., 2011]. A Root Mean Square (RMS) of about $1 \mathrm{~mm}$ in integrated water vapor is obtained by ambiguity fixed PPP with respect to the NRT products in GFZ [Li et al., 2014]. Analysis results also 
reveal that the accuracy of PPP-inferred troposphere results based on the observations of one hour can be improved from $30.1 \mathrm{~mm}$ to $17.0 \mathrm{~mm}$ by applying ambiguity resolution [Shi and Gao, 2012]. Thus, it is more suitable for the data processing of huge number of stations and also works well in RT mode thanks to the progress in generating RT satellite orbit/clock products by the International GNSS Service (IGS), as well as some other institutes and companies [Caissy et al., 2012; Gao et al., 2006; Leandro et al., 2011]. Under these circumstances, several analyses of operational RT retrieval of ZTD using PPP based on GPS observations have been conducted. Analysis results based on actual GPS RT streams and IGS RT products reveal that the PWV estimates with an accuracy of better than $3 \mathrm{~mm}$ can be obtained, which implies that the method is complementary to current atmospheric sounding systems [Ahmed et al., 2016; Dousa and Vaclavovic, 2014; Li et al., 2014; Yuan et al., 2014].

Today, GPS and GLONASS modernization are in progress [Urlichich et al., 2011], while Europe and China are also making progress in establishing their Galileo and BeiDou systems, respectively [Han et al., 2011; Montenbruck et al., 2014]. To enable scientific research concerning GNSS, the Multi-GNSS Experiment (MGEX) project was launched by the International GNSS Service (IGS) in 2011 [Rizos et al., 2013]. Recent analysis results in data quality, absolute and relative positioning revealed that the observations of these satellite systems can also be applied in high-accuracy positioning, and the performance can be further improved by combining observations from multiple systems compared to a single one [Shi et al., 2013; Tegedor et al., 2014]. Thus, it is anticipated that the accuracy of RT troposphere estimates can also be improved. Some research results in the RT retrieval of PWV using GNSS observations in a simulated mode have already validated this hypothesis [Lu et al., 2015; Li et al., 2015b]. The European Earth System Science and Environmental Management (ESSEM) COST Action ES1206 “Advanced Global Navigation Satellite Systems tropospheric products for monitoring severe weather events and climate (GNSS4SWEC)" also proposes to develop new, advanced tropospheric products utilizing GPS, GLONASS and Galileo observations to exploit the full potential of GNSS water vapor estimates ${ }^{1}$. Under this circumstance, it has become meaningful to conduct analyses of generated operational RT ZTD results based on actual RT streams of GNSS observations and evaluate the performance (initialization and accuracy) to be achieved.

In this paper, we introduce a system for extracting RT troposphere estimates utilizing a modified version of the PPP-Wizard by Centre National d'Etudes Spatiales (CNES) [Laurichesse, 2011]. An experiment of 30 days (14/02/2016 - 14/03/2016) was conducted to analyze the performance of ZTD estimates based on GPS, GLONASS and Galileo observations. The effect of RT PPP ambiguity resolution on the estimates is also evaluated. The algorithms of the software and the necessary modifications, especially in modeling the troposphere delay, are introduced in detail in section 2 . In section 3, the relevant reference data applied in the evaluation are described. The

\footnotetext{
1 http://www.cost.eu/COST_Actions/essem/Actions/ES1206
} 
experiment and analysis, as well as the analysis results, are discussed in detail in section 4. Some conclusions are drawn and the results are summarized in section 5.

\section{Algorithm of software and modifications}

The CNES proposed a method of PPP ambiguity resolution in which the narrow-lane fractional cycle biases (FCB) are assimilated into the satellite clock offsets to retain the integer properties of the narrow-lane ambiguities [Laurichesse et al., 2009]. In 2011 CNES joined the IGS RT project and has since commenced to provide relevant satellite orbit/clock products to users. At the same time as CNES provides these RT GNSS orbit/clock products, the analysis center also provides GPS phase biases information on the CNES caster (CLK93 mountpoint) [Laurichesse, 2011]. Based on these products, we can realize RT PPP with ambiguity resolution. Concurrently the RT "integer PPP" demonstrator (http://www.ppp-wizard.net/index.html) was developed to demonstrate the performance of ambiguity-fixed RT PPP. Furthermore, this software, the PPP-Wizard, was freely provided to users for assessing its potential [Laurichesse, 2011; Ahmed et al., 2016].

In this study we use a version of PPP-Wizard which is capable of processing GPS, GLONASS and Galileo observations, and applying ambiguity resolution to GPS. In the software, raw observations of all systems are processed in one parameter estimation run. The observation model for one constellation can be interpreted as follows [Laurichesse and Privat, 2015]:

$$
\begin{aligned}
& P_{1}^{\prime}=P_{1}+b_{P_{1}}=D_{1}+h+e \\
& P_{2}^{\prime}=P_{2}+b_{P_{2}}=D_{2}+h+\gamma_{2} e \\
& P_{5}^{\prime}=P_{5}+b_{P_{5}}=D_{5}+h+\gamma_{5} e \\
& \lambda_{1}\left(L_{1}^{\prime}+N_{1}\right)=\lambda_{1}\left(L_{1}+N_{1}\right)+b_{L_{1}}=D_{1}+\lambda_{1} W+h-e \\
& \lambda_{2}\left(L_{2}^{\prime}+N_{2}\right)=\lambda_{2}\left(L_{2}+N_{2}\right)+b_{L_{2}}=D_{2}+\lambda_{2} W+h-\gamma_{2} e \\
& \lambda_{5}\left(L_{5}^{\prime}+N_{5}\right)=\lambda_{5}\left(L_{5}+N_{5}\right)+b_{L_{5}}=D_{5}+\lambda_{5} W+h-\gamma_{5} e
\end{aligned}
$$

in which, $P_{i}$ and $L_{i}(i=1,2,5)$ represent the code and phase observations in each

frequency; $b_{X_{i}}(i=1,2,5)$ denotes the code and phase biases in each frequency;

$\lambda_{i}(i=1,2,5)$ is the wavelength of phase observation; $N_{i}(i=1,2,5)$ is the un-differenced

ambiguity in cycles; $D_{i}(i=1,2,5)$ includes the geometrical distance between satellite

and receiver phase center, the slant tropospheric delay, relativistic effects, etc; $h$ is the clock difference between receiver and satellite; $e$ is the slant ionospheric delay. Since the PPP-Wizard has been mainly developed for RT kinematic positioning, the observation model applied in the software is not accurate enough to fulfill the accuracy requirements of meteorological applications. Ahmed et al. (2016) highlighted this already during a comparison of free RT software available for GPS meteorology. To 
conduct our research, several modifications have been implemented in the source code by the authors to improve the performance. The updated observation model and data processing strategies in our research are listed in Table 1 in detail. Table 1 Observation model and data processing strategies in real-time troposphere estimation

\begin{tabular}{|c|c|}
\hline & Settings \\
\hline Observations & Raw pseudo-range and phase observables \\
\hline Frequency & $\begin{array}{l}\text { GPS: L1/L2/L5; GLONASS: L1/L2; Galileo: } \\
\text { E1/E5a/E5b }\end{array}$ \\
\hline Estimator & Kalman filter \\
\hline Elevation cut-off & $7^{\circ}$ \\
\hline Sampling offset & $5 \mathrm{~s}$ \\
\hline Weighting strategy & $\begin{array}{l}0.01 \mathrm{~m}, 1 \mathrm{~m} \text { for GPS phase and pseudo-range } \\
\text { observables in zenith direction; } \\
0.01 \mathrm{~m}, 10 \mathrm{~m} \text { for GLONASS/Galileo phase and } \\
\text { pseudo-range observables in zenith direction; } \\
\text { Adjust the weight between systems based on } \\
\text { the post-processing observation residuals in a } \\
\text { sliding window } \\
\text { Elevation dependent weighting; } \\
Q=1 / \sin ^{2}(\text { ele }) \text {, ele is the satellite elevation } \\
\text { as seen from the receiving antenna; }\end{array}$ \\
\hline Phase wind-up & Applied (Wu et al., 1993) \\
\hline Station displacement & Solid earth tide, ocean tide (Lyard et al., 2006) \\
\hline Receiver clock bias & Estimated as white noise \\
\hline Station coordinates & Fixed to the latest IGS SINEX files \\
\hline Inter-system/Inter-frequency bias & Estimated as constant \\
\hline Satellite antenna PCO and PCV & $\begin{array}{l}\text { Applied to GPS and GLONASS, only PCO } \\
\text { corrections applied to Galileo }\end{array}$ \\
\hline \multirow{2}{*}{ Receiver antenna PCO and PCV } & Corrected by igs08.atx (Schmid et al., 2007) \\
\hline & Apply the same values as GPS to Galileo \\
\hline Ionopsheric delay & Estimated as white noise \\
\hline
\end{tabular}

Besides that, the modeling of the slant tropospheric delay, which is the main interest of the research, has been improved as it affects the GNSS observations in adding an extra delay to the measurements when the signals travel through the neutral atmosphere. This refinement can be expressed as follows [Dach et al., 2007]:

$$
T=z_{h} \bullet m f_{h}+z_{w} \bullet m f_{w}
$$

in which $z_{h}, z_{w}$ are the zenith hydrostatic delay (ZHD) and zenith non-hydrostatic(wet)

delay (ZWD) in meters, $m f_{h}, m f_{w}$ represent the mapping function for the hydrostatic and non-hydrostatic part respectively. In this analysis, the Global Mapping Function (GMF) [Boehm et al., 2006] is applied, while no gradient parameters are estimated. We 
would expect a small improvement from their inclusion [Li et al. 2015a] and will address this in a future step.

ZHD, which accounts for $90 \%$ of the troposphere delay, can be accurately calculated based on a-priori models. We adopt the Global Pressure and Temperature (GPT) model [Boehm et al., 2007] to compute the temperature and pressure values, and input to the Saastamoinen model [Saastamoinen, 1973; Davis et al., 1985] to calculate the ZHD. Since it is difficult to model the ZWD, it is estimated as an unknown parameter. In RT data processing, ZWD is modeled as a random walk process using the following equation:

$$
z_{w}\left(t_{i+1}\right)=z_{w}\left(t_{i}\right)+\varepsilon, \varepsilon \square N\left(0, \sigma_{0}^{2} \bullet \Delta t\right)
$$

where $z_{w}\left(t_{i}\right)$ denotes the ZWD at epoch $t_{i}, \varepsilon$ is the temporal variation of ZWD

between epoch $t_{i}$ and $t_{i+1}, \sigma_{0}$ is the noise intensity of ZWD and set to $5 . e^{-5} \mathrm{~m} / \sqrt{s}$ in the analysis, $\Delta t$ denotes the time difference between two epochs.

\section{Reference data}

To fully analyze the performance of the RT troposphere estimates, two sources of reference data are applied in the analysis.

\subsection{Final troposphere products}

We select the final troposphere products generated by the Center for Orbit

Determination in Europe (CODE) and the US Naval Observatory (USNO) as reference data sets in our analysis. The sampling interval of the CODE products is 2 hours and about 250 stations are processed using the Bernese GNSS Software Version 5.3 [Dach et al., 2015] during the period analyzed. The elevation cut-off angle is 3 degrees and the Vienna Mapping Function (VMF) [Boehm and Schuh, 2003; Kouba, 2008] is applied. The sampling interval of the USNO products is 5 minutes, which is generated using PPP as implemented in the Bernese GPS Software Version 5.0 [Dach et al., 2007] based on the IGS final orbit/clock products. The GMF mapping function is applied at USNO [Byram and Hackman, 2012]. The accuracy of these two products is about $4 \mathrm{~mm}$ with respect to the troposphere results generated by other independent measurement techniques, e.g., VLBI, DORIS, radiosondes and numerical weather models [Dow et al., 2009; Yuan et al., 2014; Dach and Jean, 2015]. Since these two products are also calculated from GNSS observations, which is the same as our RT troposphere results, it provides a good opportunity to evaluate the impact of RT satellite orbit/clock products and the data processing strategy.

\subsection{Radiosonde observations}

Radiosonde observations are recorded during the ascend of the unit up to $30 \mathrm{~km}$ and include pressure, temperature and dew point temperature, which can be converted to water vapor partial pressure. These observations provide an important source for upper air information. They are given in vertical profiles with different number of layers 
depending on the weather conditions and sonde performance. For the majority of stations, the number of layers is between 20 and 60. ZTD can be integrated based on these radiosonde profiles and provides an independent method for evaluating the accuracy of the RT troposphere results generated in this analysis.

The radiosonde observations are downloaded from the National Oceanic and Atmospheric Administration (NOAA) Earth System Research Laboratory (ESRL) radiosonde database (http://esrl.noaa.gov/raobs/), and applied to calculate ZTD based on the method proposed in Haase et al. [2003]. The geoid values from the 2008 release of the Earth Geoid Model (EGM) [Pavlis et al., 2012] are applied to convert the geopotential heights to ellipsoidal heights. No horizontal corrections are made during the process. In addition, an outlier detection process is employed to screen out the outliers in the comparison [Dousa and Bennitt, 2013].

\section{Experiment and analysis results}

An experiment, which lasted for 30 days (14/02/2016 - 14/03/2016), was conducted to analyze the performance of RT troposphere estimates. The ZTDs were estimated every 5 seconds. Five data processing modes, as listed in Table 2, were established to evaluate the impact of the GNSS observations and PPP ambiguity resolution. The first two modes were established to analyze the accuracy which can be achieved based on the observations of a single system. The third mode was established to show the improvements of RT PPP ambiguity resolution, while the improvement utilizing GNSS observations was evaluated in the fourth mode. The final accuracy achieved was shown in the last mode. Since only a few Galileo satellites can be tracked during the experiment and the accuracy of RT Galileo satellite orbits/clocks is relatively low, no Galileo-only results were generated.

Table 2 List of data processing modes

\begin{tabular}{ll}
\hline Modes & Details \\
\hline RFLT & Float PPP solution based on GLONASS-only observations \\
\hline GFLT & Float PPP solution based on GPS-only observations \\
\hline GFIX & Fixed PPP solution based on GPS-only observations \\
\hline MFLT & Float PPP solution based on GPS/GLONASS observations \\
\hline MFIX & Fixed PPP solution based on GPS/GLONASS/Galileo observations \\
\hline
\end{tabular}

A total of 20 IGS/MGEX stations were selected in the experiment. Among them, 11 stations (denoted as red circles) can track GPS/GLONASS/Galileo satellites, while another 9 stations (denoted as blue circles) can only track GPS/GLONASS satellites. The distribution of these stations is shown in Figure 1. 


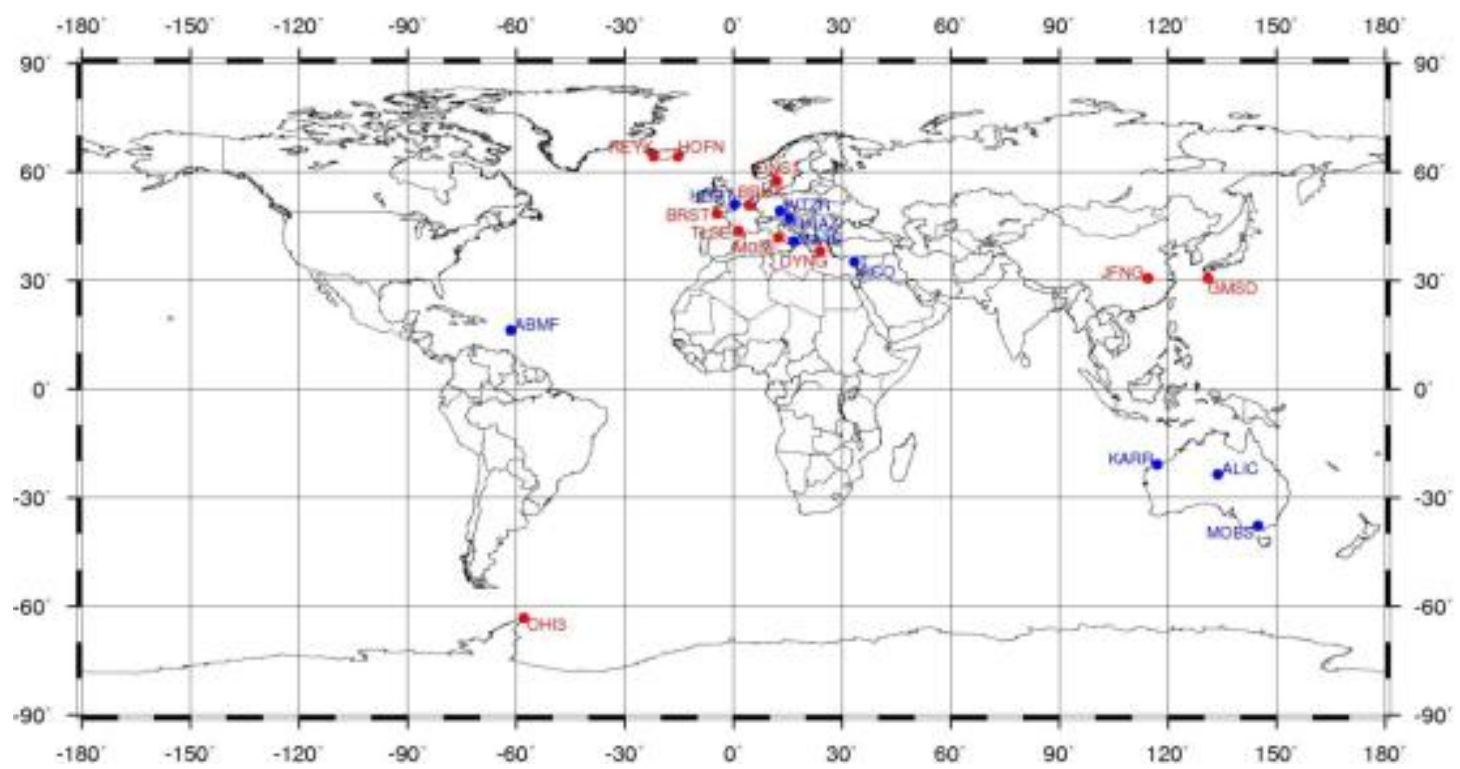

Figure 1 Distribution of IGS/MGEX stations in the experiment

\subsection{Initialization analysis}

Figure 2 plots the number of satellites tracked by station BRST on Day of Year (DOY) 45,2016 , and the situations of other stations are similar. We can notice that at least six GPS and three GLONASS satellites were tracked by the station apart from several epochs affected by signal loss of lock. The mean numbers of satellites tracked were 9 and 7 each. In addition, several Galileo satellites were tracked, reaching a maximum of four during about two hours of one day. In total, 17 satellites were tracked on average.

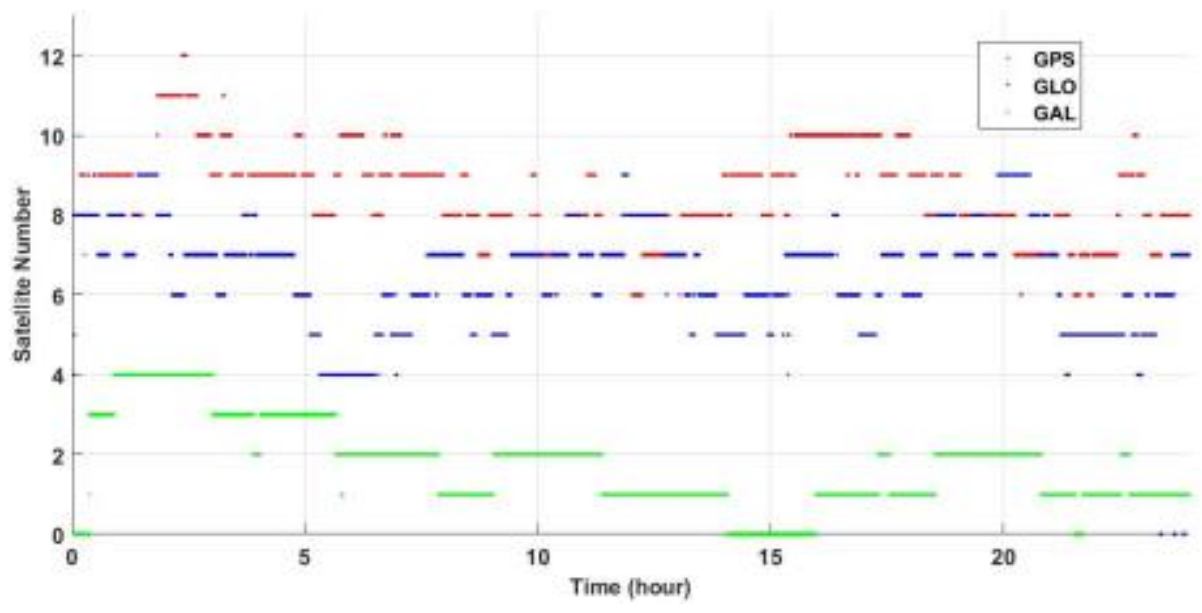

Figure 2 Number of satellites tracked by station BRST on DOY 45, 2016

Figure 3 shows the RT ZTD estimates of all data processing modes for the first two hours of DOY45, 2016. As expected, an initialization period is visible for all solutions. After that, the differences between the solutions become small, which reveals that similar troposphere results can be achieved in all modes. During the initialization process, the inconsistency of the RFLT solution is the largest with respect to other solutions. The variation of the GFLT and GFIX solutions is very similar, and it is also the same for the MFLT and MFIX solutions, except a jump in the fixed solution because of incorrect ambiguity resolution of one satellite. Compared with this, the 
differences between those solutions based on the observations of different satellite systems are relatively bigger.

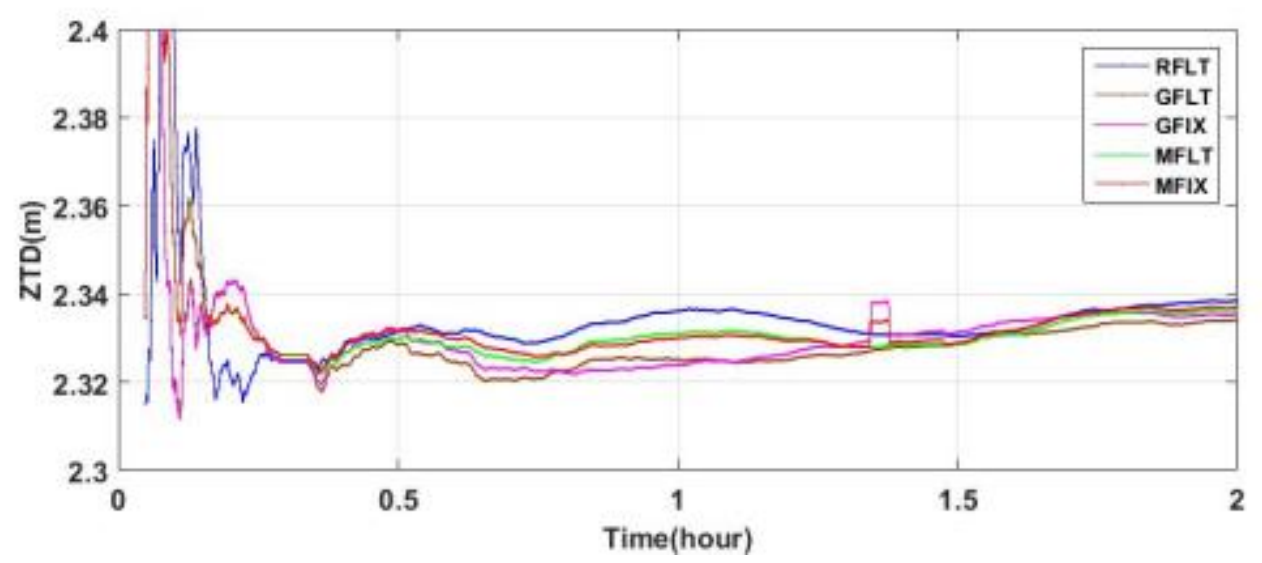

Figure 3 RT ZTD of station BRST in all data processing modes in the first two hours of DOY 45, 2016

To evaluate the initialization time required, the observations are processed every 2 hours separately. The initialization process is considered to be finished each time when the differences between estimated troposphere results and the final troposphere products from USNO become and remain smaller than a given value for 1.5 hours or until the end of the session. In this analysis, we set the value to $20 \mathrm{~mm}$, which is the threshold value for weather now-casting [De Haan, 2006].

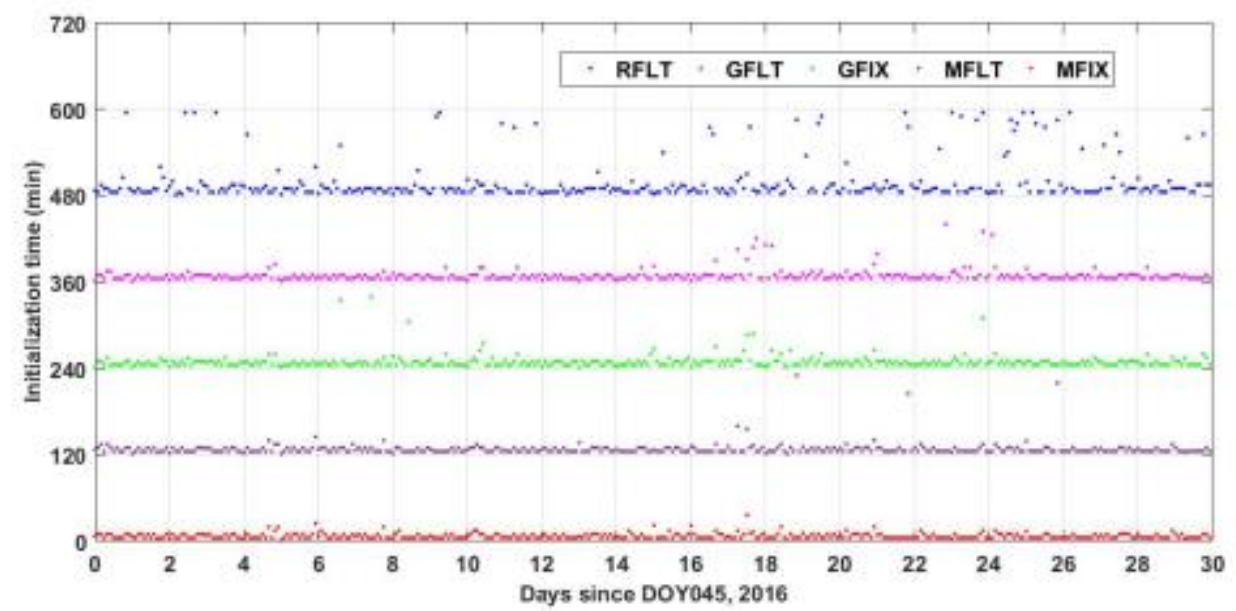

Figure 4 plots the initialization time for BRST during each session in all data processing modes, and the results for all the stations are plotted separately in the supporting information (Figure S1). The results of RFLT, GFLT, GFIX and MFLT solutions are shifted 480, 360, 240, and 120 minutes each to show the results clearly. It can be found that the initialization process of RFLT is the longest. In addition, the initialization process is not finished after two hours, which decreases the reliability in tracking severe weather change using GLONASS-only observations. When utilizing GPS-only observations, a long time is still required during some sessions, but nearly all the processes are finished within 1 hour. The performance becomes better in both GFIX 
and MFLT solutions, and the best performance is achieved in the MFIX solution with an average value of 7 minutes.

Following on, we summarize the average initialization time required for all stations in each data processing mode. The results are plotted in

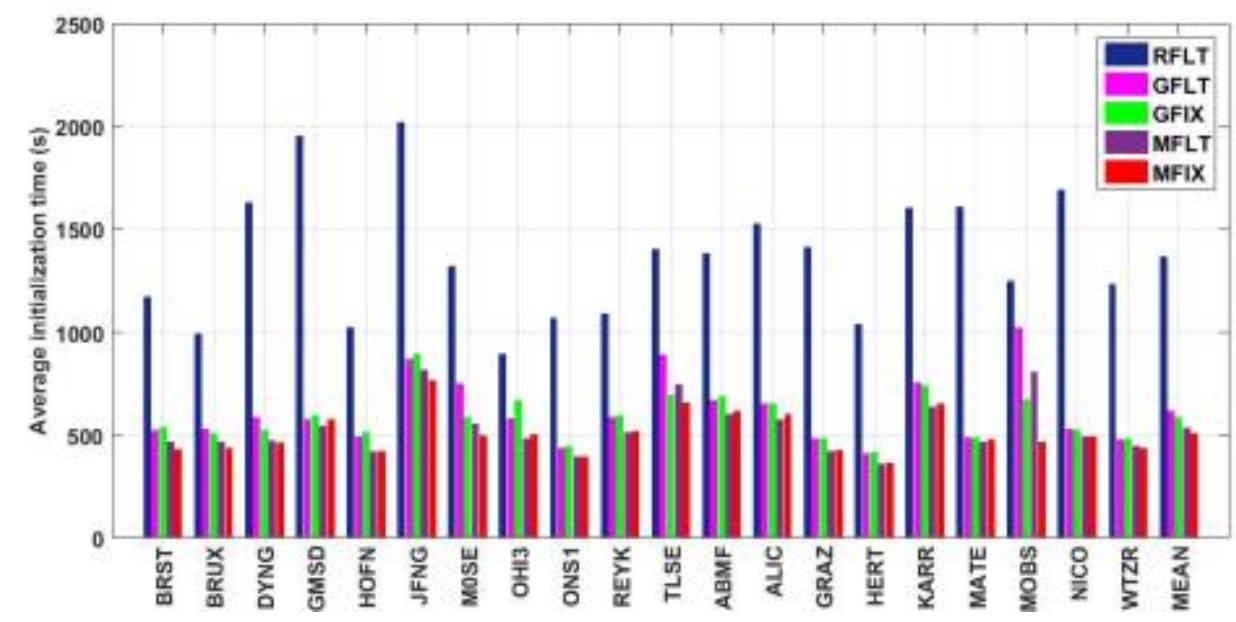

Figure 5. It can be found that the initialization time required by the RFLT solution is still the longest. It exceeds 30 minutes for two stations. Compared with that, the initialization time for the GFLT solution is shorter for all stations. The average value is $613 \mathrm{~s}$ ( $10.2 \mathrm{~min})$. By applying ambiguity resolution, the initialization time becomes shorter for most of the stations, and is $583.6 \mathrm{~s}(\sim 9.7 \mathrm{~min})$ on average. The initialization process can also be accelerated by utilizing GNSS observations, for which it can be achieved on average in $533 \mathrm{~s}(\sim 8.9 \mathrm{~min})$. Again, this suggests that the effect of the observation geometry is larger than that of ambiguity resolution in accelerating the initialization process, especially considering that an initialization time is required to achieve the first ambiguity resolution. When applying all techniques in the MFIX solution, the initialization process is finished in $508.3 \mathrm{~s}(\sim 8.5 \mathrm{~min})$ on average, and there are only small difference between different stations, which reveals the benefit of GNSS observation and ambiguity resolution for severe weather event monitoring.

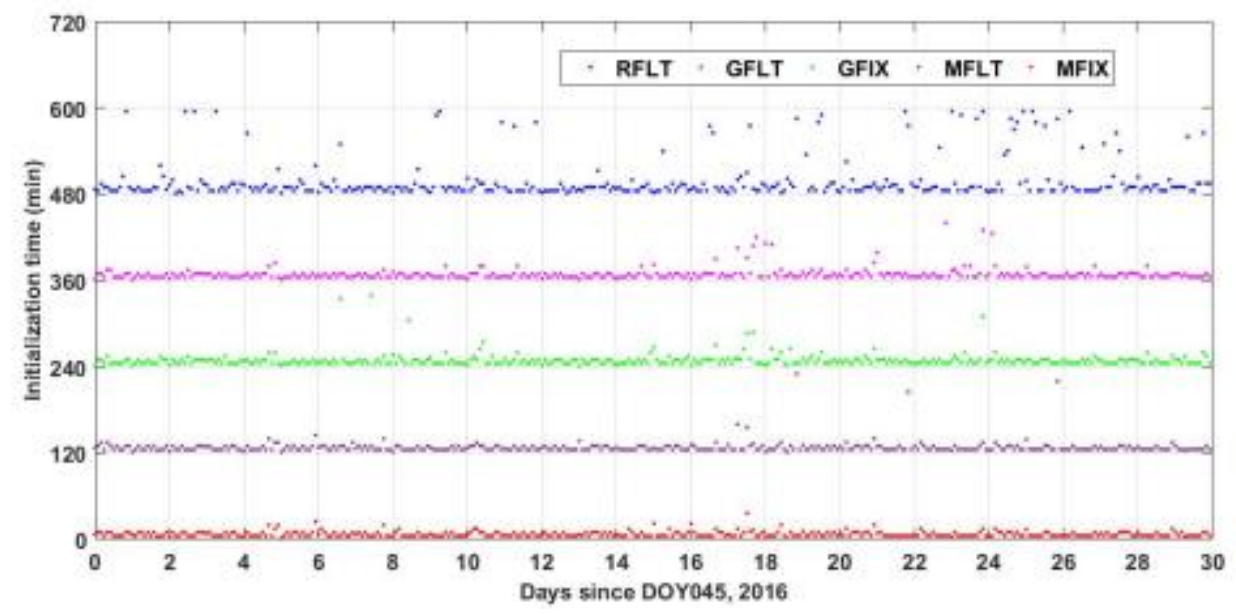

Figure 4 Initialization time of BRST in all data processing modes 


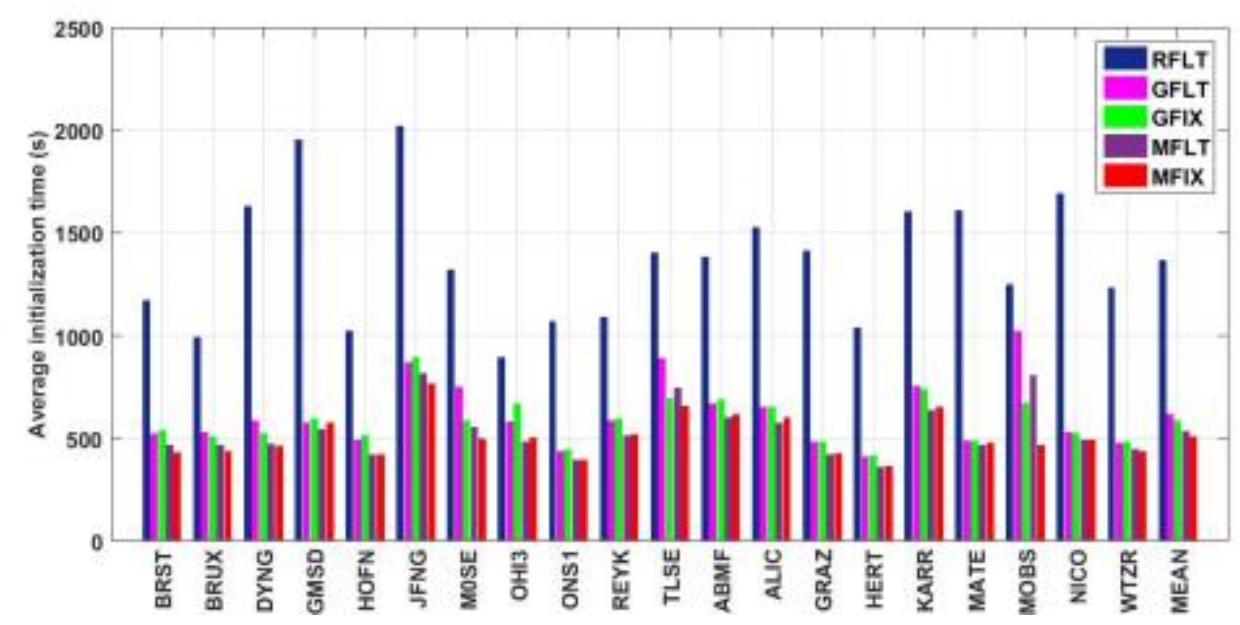

Figure 5 Average initialization time in all data processing modes

\subsection{Accuracy analysis}

To analyze the accuracy of RT troposphere estimates achieved, we processed the data continuously for the whole period and compared our solutions with two types of reference data (final troposphere products, and radiosonde observations). In the comparison, we only calculate the differences after convergence. In addition, only the data in the same epochs are compared to eliminate the impact of interpolation on the evaluation results.

\subsubsection{Comparison with final troposphere products}

We present the RT ZTD differences for BRST with respect to the final troposphere products from USNO in Figure 6. The consistency with respect to other data processing modes is also the worst, and the differences become much bigger during some periods, which corresponds with fewer GLONASS satellites. Compared with that, the GFLT solution is better.The differences are smaller than $4 \mathrm{~cm}$ except a few epochs. When combining the observations of both systems in the MFLT solution, the RT ZTD differences become stable, and several periods with big errors disappear. This can be attributed to the larger number of satellites tracked and the improvement in the observation geometry. The performance is also improved by applying ambiguity resolution in the GFIX solution. The accuracy will be strongly correlated with the RT phase bias information. When applying all techniques in the MFIX solution, the most stable solution can be achieved with an RMS of $7.0 \mathrm{~mm}$ during the day. 


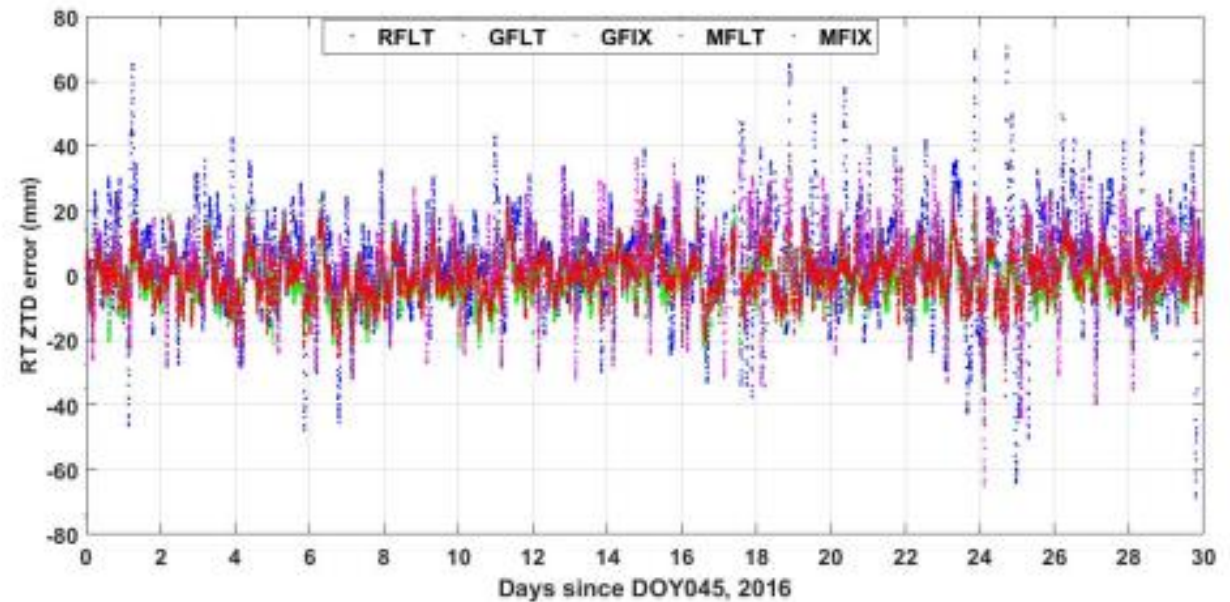

Figure 6 RT ZTD error of station BRST with respect to final troposphere products from USNO on DOY45, 2016
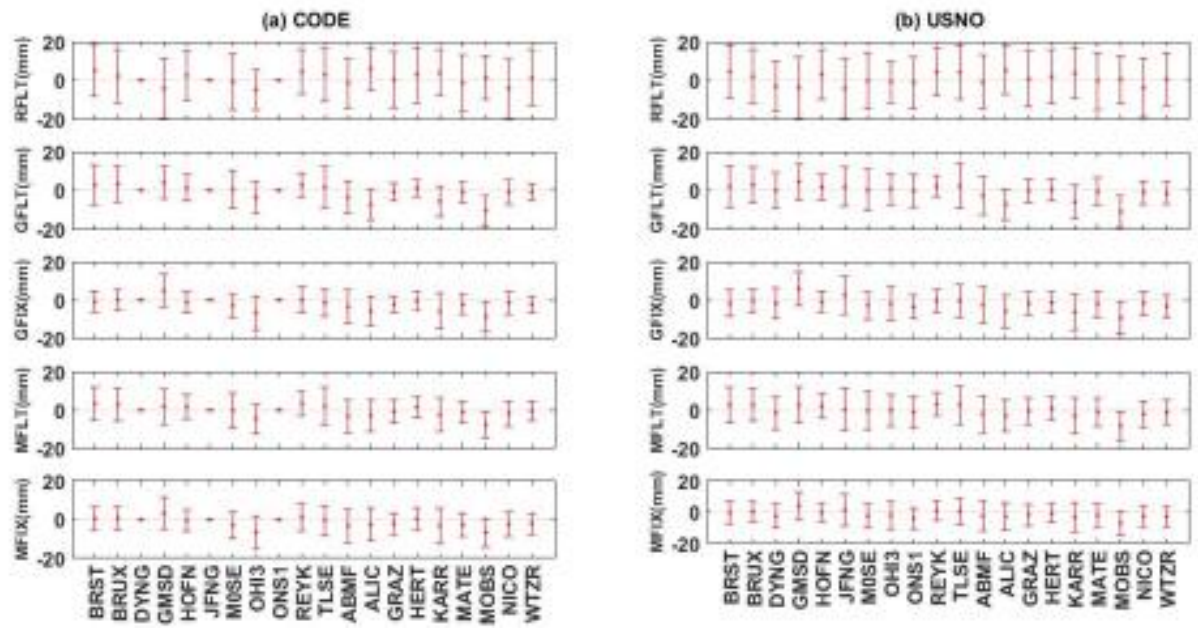

Figure 7 Accuracy of RT troposphere results with respect to the final troposphere products from CODE (left) and USNO(right)

Table 3 Average accuracy of all data processing modes with respect to final troposphere products

\begin{tabular}{ccccccc}
\hline & \multicolumn{3}{c}{ CODE } & \multicolumn{3}{c}{ USNO } \\
\cline { 2 - 7 } & Mean $(\mathrm{mm})$ & STD $(\mathrm{mm})$ & RMS $(\mathrm{mm})$ & Mean $(\mathrm{mm})$ & STD $(\mathrm{mm})$ & RMS $(\mathrm{mm})$ \\
\hline RFLT & 0.82 & 11.26 & 11.61 & 0.61 & 13.67 & 13.98 \\
\hline GFLT & -0.83 & 6.32 & 7.05 & -0.59 & 8.27 & 8.95 \\
\hline GFIX & -2.09 & 5.65 & 6.37 & -2.03 & 7.45 & 8.17 \\
\hline MFLT & -0.47 & 6.41 & 6.87 & -0.41 & 8.27 & 8.69 \\
\hline MFIX & -1.48 & 5.96 & 6.42 & -1.52 & 7.69 & 8.14 \\
\hline
\end{tabular}

Figure 7 plots the mean bias and standard deviation (STD) of all stations with respect to the final troposphere products from CODE and USNO. The actual values for all stations in each mode are provided in the supporting information (Table S1), and the average accuracy for all data processing modes are summarized in Error! Reference source not found.. The statistics with respect to the two types of products is similar, which further validates the reliability and consistency of the reference products. The RMS of the RFLT solution for nearly all stations is smaller than $15 \mathrm{~mm}$, and the average value is about 11.16 and $13.98 \mathrm{~mm}$ with respect to the final troposphere 
products from CODE and USNO. Compared with that, the RMS of the GFLT solution is better. The RMS of all stations is better than $12 \mathrm{~mm}$ except MOBS, and is about $9 \mathrm{~mm}$ on average. The worse performance of the RFLT solution may come from two points: 1) the accuracy of satellite products for GLONASS is worse than for GPS [Dach and Jean, 2015]; 2) similar to the situation in Figure 2, the number of GLONASS satellites is less than for GPS. However, considering the accuracy requirements (10-15mm) in updating NWP models, the RT troposphere estimates based on GPS or GLONASS only observations can both fulfill the requirements [De Haan, 2006].

Applying ambiguity resolution, the GFIX solution is further improved up to $0.8 \mathrm{~mm}$ on average compared to the GFLT solution. However, the mean bias becomes slightly bigger. Combining the observations of two systems, the MFLT solution is only 0.18 $\mathrm{mm}$ and $0.26 \mathrm{~mm}$ improved on average with respect to CODE and USNO products, which reveals that the accuracy is not greatly improved by incorporating GLONASS observations. In addition, the accuracy even becomes a little worse for some stations, which may be correlated with the weighting strategy between two systems and needs further research in the future. At last, the mean RMS of the MFIX solution is $6.42 \mathrm{~mm}$ and $8.14 \mathrm{~mm}$ respectively. It is the best solution among all the data processing modes, which again reveals the effect in utilizing GNSS observations and ambiguity resolution.

\subsubsection{Comparison with radiosonde observations}

In this analysis, the comparison is applied to those IGS/MGEX stations with nearby radiosonde stations within $80 \mathrm{~km}$. In addition, station BRUX is ignored in the analysis as no observations from a nearby radiosonde station exist in the database for the period analyzed. In total, the comparison results are generated for 13 stations.

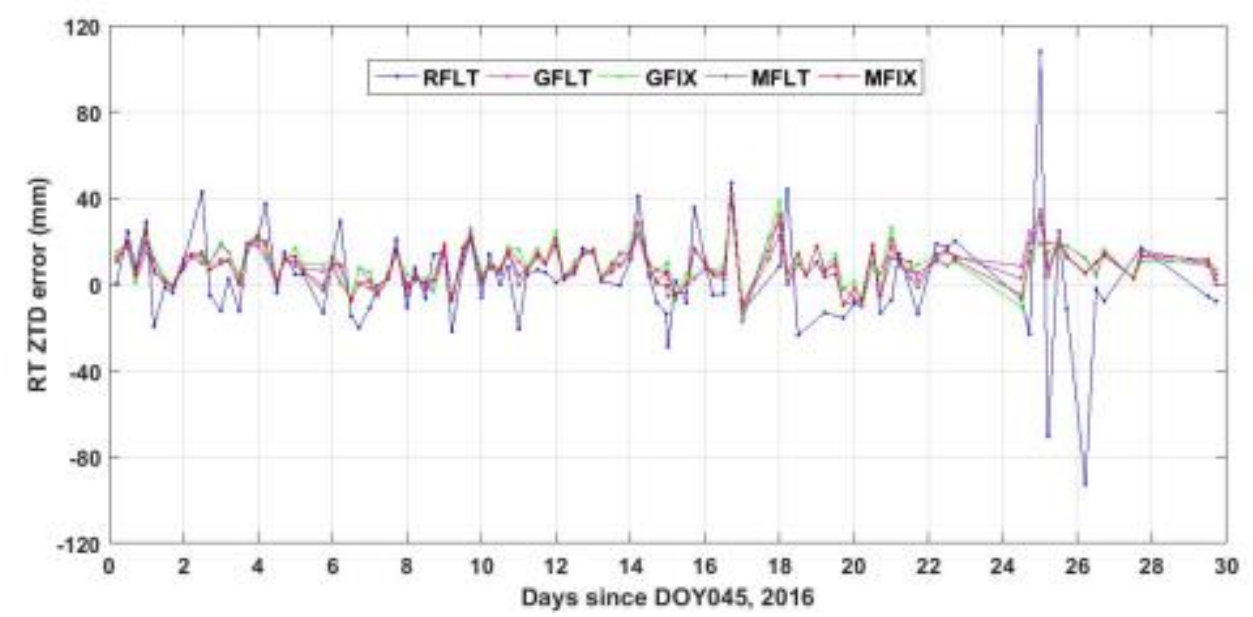

Figure 8 shows the RT ZTD difference of WTZR with respect to the radiosonde observations in all data processing modes. As we can see, all the differences are within $4 \mathrm{~cm}$ except some outliers in the single system solution. Among the solutions, we can again find that the RFLT solution is worst in both accuracy and reliability. The STD 
of the difference of another four solutions with respect to the radiosonde observations are about $9 \mathrm{~mm}$.

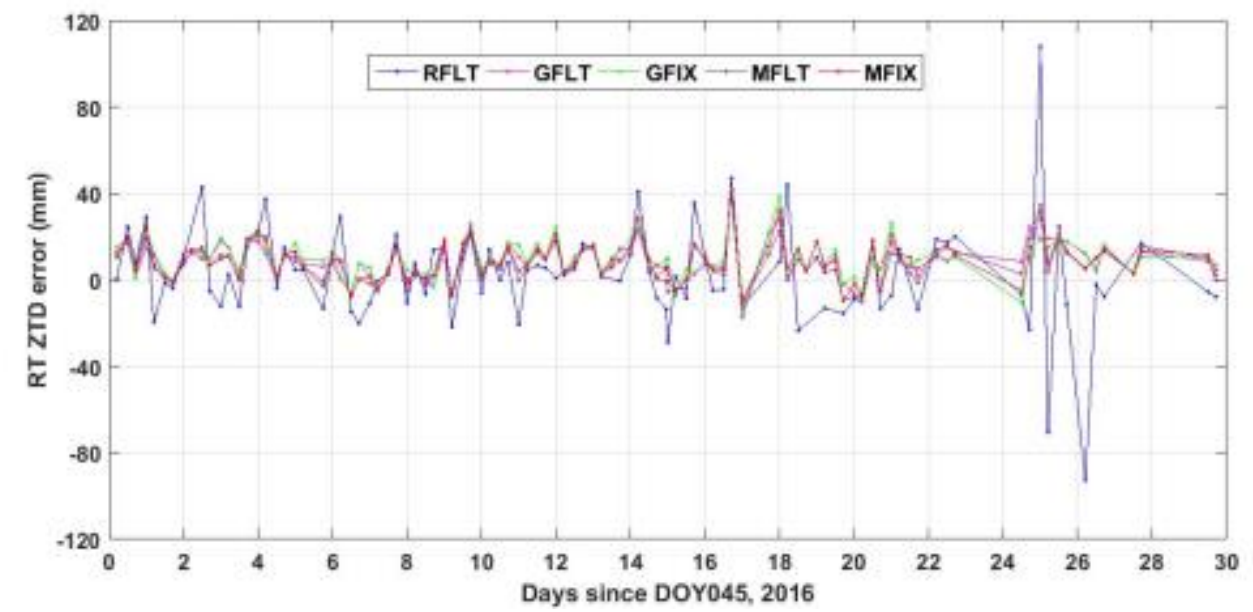

Figure 8 RT ZTD error of WTZR with respect to radiosonde observations

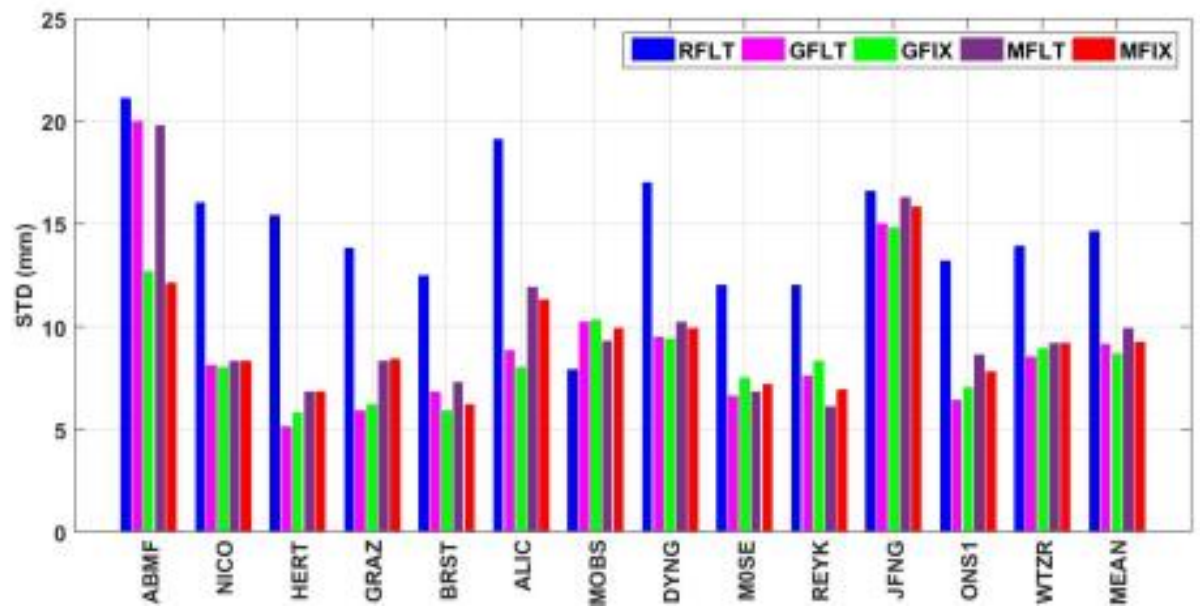

Figure 9 STD of RT ZTD errors with respect to the radiosonde observations in all data processing modes

To summarize the accuracy of the 13 stations, we sort the results based on the distance between the GNSS station and the nearby radiosonde station. Since the mean bias of RT ZTD are monitored and will be corrected in the assimilation procedure, we will only calculate the STD of all stations [Bennitt and Jupp, 2012]. The results 
between different solutions are shown in

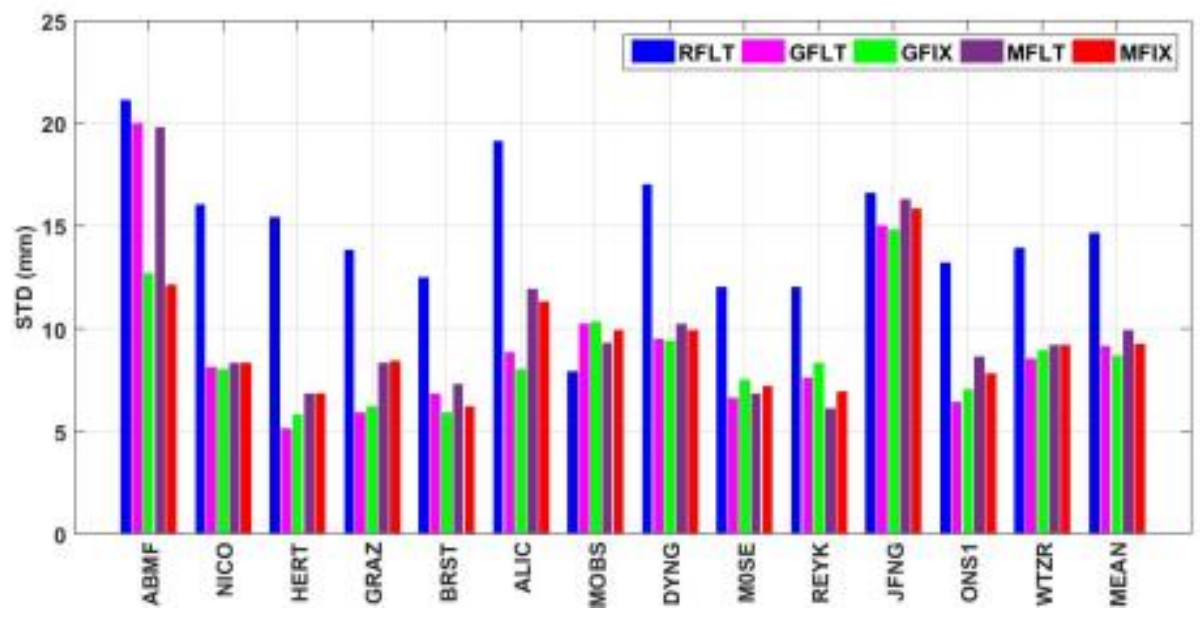

Figure 9. Based on the results, the accuracy of the RFLT solution is the worst, of which the STD is especially larger and exceeds $15 \mathrm{~mm}$ in several stations. Among the other solutions, the STDs are all smaller than $15 \mathrm{~mm}$ except for ABMF and JFNG. On average, the STDs of the two single system solutions are $14.6 \mathrm{~mm}$ and $9.1 \mathrm{~mm}$ each, which again reveals that they can fulfill the requirements in monitoring severe weather events.

However, compared with the GFLT solutions, we notice that the accuracies of the GFIX and MFLT solutions become a little lower for many stations. Since there is only one radiosonde observation in each day, this might be a consequence of the instability of GPS phase bias information and the satellite orbit/clock products for GLONASS. Further work in improving the robustness of GNSS solution is also required.

\section{Conclusions}

In this paper, an operational system for extracting zenith troposphere delay from GPS/GLONASS/Galileo observations in real-time (RT) based on RT satellite orbit/clock products is established using a modified version of PPP-Wizard. We have conducted a detailed analysis of the initialization time and accuracy of RT ZTD estimates utilizing the IGS/MGEX RT streams and the RT satellite products from CNES.

Concerning the convergence, the results reveal that an average initialization time of $1364 \mathrm{~s}$ and $613 \mathrm{~s}$ respectively based on GLONASS-only and GPS-only observations is required. The initialization process can be accelerated by both RT PPP ambiguity resolution and utilizing GNSS observations. In addition, it can be concluded that the improvement is larger when adding the additional observations, which reveals that the observing geometry is more effective in accelerating the convergence of RT troposphere estimates. When combining all techniques, the initialization process can be finished in an average time of $508 \mathrm{~s}$.

In terms of accuracy, the comparison results with respect to the final troposphere results from CODE and USNO, as well as the radiosonde observations, reveal that the RT troposphere estimates generated by single or multi system observations can all 
fulfill the accuracy requirements for now-casting. Different from the initialization process, RT PPP ambiguity resolution can improve the accuracy more than combining GNSS observations. This might be caused by the relatively low accuracy of GLONASS-only solution and the problem of the weighting strategy between the systems. Still, the best solution can be achieved for the MFIX solution with an average RMS of about $8 \mathrm{~mm}$. It reveals that the effect of GNSS observation and ambiguity resolution in RT meteorological applications, and is anticipated that the performance might be further increased by improving the GLONASS-only solution and incorporating more Galileo and BeiDou satellites in the near future. In addition, we found from the comparison results with the radiosonde observations that the performance of GFIX and MFLT solutions is lower than the GFLT solution, which suggests that the stability of GPS phase bias information and satellite products for GLONASS may have to be further improved. Further researches in improving the robustness of GNSS solutions are also required.

\section{Acknowledgements}

This project is funded by the Fonds National de la Recherche, Luxembourg (Reference No. 6823109) and the National Natural Science Foundation of China (Grant No. 41404017). We acknowledge IGS, MGEX for providing the GNSS data. The final troposphere products from CODE and USNO are highly appreciated. We also thank NOAA in providing the radiosonde observations.

\section{References}

Ahmed, F., P. Václavovic, F. N. Teferle, J. Douša, R. Bingley, and D. Laurichesse (2016), Comparative analysis of real-time precise point positioning zenith total delay estimates, GPS Solut., 20(2), 187-199, doi:10.1007/s10291-014-0427-z.

Bennitt, G., and T. Levick (2011), The impact of assimilating zenith total delay measurements from ground-based GNSS receivers in the Met Office numerical weather prediction UK model, Geophys Res Abstr, 13, EGU2011-6705.

Bennitt, G., and A. Jupp (2012), Operational assimilation of GPS Zenith total delay observations into the UK Met Office numerical weather prediction models. Mon. Weather Rev., 140(8), 2706-2719, doi:10.1175/MWR-D-11-00156.1

Bevis, M., S. Businger, T. A. Herring, C. Rocken, R. A. Anthes, and R. H. Ware (1992), GPS meteorology: remote sensing of atmospheric water vapor using GPS, J. Geophys. Res., 97, 15787-15801, doi:10.1029/ 92JD01517.

Bock, O., P. Willis, J. Wang, and C. Mears (2014), A high-quality, homogenized, global, long-term (1993-2008) DORIS precipitable water data set for climate monitoring and model verification, J. Geophys. Res., 119(12), 7209-7230, doi:10.1002/2013JD021124.

Boehm, J., and H. Schuh (2003), Vienna Mapping Functions, in Proceedings of the 16th Working Meeting on European VLBI for Geodesy and Astrometry, Leipzig, May 9-10, 2003, 131-143, Verlag des Bundesamtes für Kartographie und Geodaesie. 
Boehm, J., A. Niell, P. Tregoning, and H. Schuh (2006), Global mapping function (GMF): a new empirical mapping function based on numerical weather model data, Geophys. Res. Lett., 33, L07304, doi:10.1029/2005GL025546.

Boehm, J., R. Heinkelmann, and H. Schuh (2007), Short note: A global model of pressure and temperature for geodetic applications, J. Geod., 81(10), 679-683, doi:10.1007/s00190-007-0135-3.

Byram, S., and C. Hackman (2012), High-precision GNSS orbit, clock and EOP estimation at the United States Naval Observatory, 2012 IEEE/ION Position, Location and Navigation Symposium, PLANS 2012, 659-663 , doi:10.1109/ PLANS.2012.6236940.

Caissy, M., L. Agrotis, G. Weber, M. Hernandez-Pajares, and U. Hugentobler (2012), Coming Soon: The International GNSS Real-Time Service, GPS World, 23(6), 52.

Coster, A. J., A. E. Niell, F. S. Solheim, V. B. Mendes, P. C. Toor, K. P. Buchmann, and A. Upham (1996), Measurements of precipitable water vapor by GPS, radiosondes, and a microwave water vapor radiometer, In: Proceedings of ION GPS-96, Kansas City, MO, 17-20 September 1996, 625-634.

Dach, R., and R. Dietrich (2000), Influence of the ocean loading effect on GPS derived precipitable water vapor, Geophys. Res. Lett., 27(18), 2953-2956, doi:10.1029/1999GL010970.

Dach, R., U. Hugentobler, P. Fridez, and M. Meindl (2007), Bernese GPS Software Version 5.0, AIUB, University of Bern, Switzerland.

Dach, R., S. Lutz, P. Walser, and P. Fridez (2015), Bernese GNSS Software Version 5.2, Astronomical Institute, University of Bern, Bern.

Dach, R., and Y. Jean (2015), International GNSS Service, Technical Report 2014, IGS Central Bureau, Pasadena, California

Davis, J., T. Herring, I. Shapiro, A. Rogers, and G. Elgered (1985), Geodesy by radio interferometry: effects of atmospheric modeling errors on estimates of baseline length, Radio Sci., 20(6), 1593-1607, doi:10.1029/RS020i006p01593.

De Haan, S. (2006), National/regional operational procedures of GPS water vapour networks and agreed international procedures, Rep WMO/TD-No, 1340:20, KNMI, Netherlands.

De Haan, S. (2011), Impact of GPS ZTD on rainfall estimates in an hourly update cycle of a numerical weather prediction model, Geophys. Res. Abstr., 13, EGU2011-4222.

Dodson, A. H., P. J. Shardlow, L. C. M. Hubbard, G. Elgered, and P. O. J. Jarlemark (1996), Wet tropospheric effects on precise relative GPS height determination, J. Geod., 70(4), 188-202, doi:10.1007/BF00873700.

Dousa, J. (2001a), Towards an operational near-real time precipitable water vapor estimation, Phys. Chem. Earth A, 26(3), 189-194, doi:10.1016/S1464-1895(01)00045-X.

Dousa, J. (2001b), The impact of ultra-rapid orbits on precipitable water vapor estimation using ground GPS network, Phys. Chem. Earth A, 26(6-8), 393-398, doi:10.1016/S1464-1895(01)00072-2. 
Dousa, J., and G. V. Bennitt (2013), Estimation and evaluation of hourly updated global GPS Zenith Total Delays over ten months, GPS Solut., 17(4), 453-464, doi:10.1007/s10291-012-0291-7.

Dousa, J., and P. Vaclavovic (2014), Real-time zenith tropospheric delays in support of numerical weather prediction applications, Adv. Space Res., 53(9), 1347-1358, doi: 10.1016/j.asr.2014.02.021.

Dow, J., R. E. Neilan, and C. Rizos (2009), The International GNSS Service in a changing landscape of Global Navigation Satellite Systems, J. Geod., 83(7), 191-198, doi:10.1007/s00190-008-0300-3.

Duan, J., et al (1996), GPS meteorology: direct estimation of the absolute value of precipitable water, J. Appl. Meteorol., 35(6), 830-838, doi:10.1175/1520-0450(1996)0352.0.CO;2.

Gao, Y., Y. Zhang, and K. Chen (2006), Development of a real-time single-frequency Precise Point Positioning system and test results, Proceedings of ION GNSS 2006, 26-29 September, Fort Worth, Texas, 2297-2303.

Ge, M., E. Calais, and J. Haase (2002), Sensitivity of zenith total delay accuracy to GPS orbit errors and implications for near-real-time GPS meteorology, J. Geophys. Res., 107(D16), 4315, doi:10.1029/2001JD001095.

Ge, M., G. Gendt, M. Rothacher, C. Shi, and J. Liu (2008), Resolution of GPS carrier-phase ambiguities in precise point positioning (PPP) with daily observations, J. Geod., 82(7), 389-399, doi:10.1007/s00190-007-0187-4.

Gendt, G., C. Reigber, and G. Dick (2001), Near real-time water vapor estimation in a German GPS network-first results from the ground program of the HGF GASP project, Phys. Chem. Earth A, 26(6-8), 413-416, doi:10.1016/S1464-1895(01)00075-8.

Geng, J., F. N. Teferle, X. Meng, and A. H. Dodson (2011), Towards PPP-RTK: Ambiguity resolution in real-time precise point positioning, Adv. Space Res., 47(10), 1664-1673, doi:10.1016/j.asr.2010.03.030.

Gradinarsky L.P., and G. Elgered (2000), Horizontal gradients in the wet path delay derived from four years of microwave radiometer data, Geophys. Res. Lett., 27(16), 2521-2524, doi: 10.1029/2000GL011427.

Guerova, G., J. Jones, J. Dousa, G. Dick, S. de Haan, E. Pottiaux, O. Bock, R. Pacione, G. Elgered, H. Vedel (2013), Advanced global navigation satellite systems tropospheric products for monitoring severe weather events and climate (GNSS4SWEC), In: 4th international colloquium scientific and fundamental aspects of the Galileo programme, Prague, Czech Republic, 4-6 December, 2013.

Gutman, S.I., S.G. Benjamin (2001), The role of ground-based GPS meteorological observations in numerical weather prediction, GPS Solut, 4(4), 16-24, doi: 10.1007/PL00012860.

Haase, J., H. Vedel, M. Ge, and E. Calais (2001), GPS zenith troposphere delay (ZTD) variability in the Mediterranean, Phys. Chem. Earth A, 26, 439-443, doi:10.1016/S1464-1895(01)00080-1.

Haase, J., M. Ge, H. Vedel, and E. Calais (2003), Accuracy and variability of GPS tropospheric delay measurements of water vapor in the western Mediterranean, J. 
Appl. Meteorol., 42, 1547-1568, doi:http://dx.doi.org/10.1175/1520-0450(2003)042<1547:AAVOGT>2.0.CO;2.

Han, C., Y. Yang, and Z. Cai (2011), BeiDou navigation satellite system and its time scales, Metrologia, 48, S213-S218, doi:http://dx.doi.org/10.1088/0026-1394/48/4/S13.

Karabatic, A., R. Weber, and T. Haiden (2011), Near real-time estimation of tropospheric water vapour content from ground based GNSS data and its potential contribution to weather now-casting in Austria, Adv. Space Res., 47, 1691-1703, doi:10.1016/j.asr.2010.10.028.

Kouba, J. (2008), Implementation and testing of the gridded Vienna Mapping Function 1 (VMF1), J. Geod., 82(4-5), 193-205, doi:10.1007/s00190-007-0170-0.

Laurichesse, D., F. Mercier, J. P. Berthias, P. Broca, and L. Cerri (2009), Integer ambiguity resolution on undifferenced GPS phase measurements and its application to PPP and satellite precise orbit determination, Navig. J. Inst. Navig., 56(2), 135-149, doi:10.1002/j.2161-4296.2009.tb01750.x.

Laurichesse, D., F. Mercier, and J. Berthias (2010), Real-time PPP with undifferenced integer ambiguity resolution, experimental results, Proceedings of ION GNSS 2010, Portland, Oregon, 2534-2544.

Laurichesse, D. (2011), The CNES real-time PPP with un-differenced integer ambiguity resolution demonstrator, Proc. ION GNSS 2011, Portland, Oregon, 19-23 September, 654-662.

Laurichesse, D., L. Cerri, J. Berthias, and F. Mercier (2013), Real-time Precise GPS Constellation and Clocks Estimation by Means of a Kalman Filter, Proc. ION GNSS 2013, Nashville, Tennessee, 16-20 September, 1155-1163.

Laurichesse, D., and A. Privat (2015), An Open-source PPP Client Implementation for the CNES PPP-WIZARD Demonstrator, Proc. ION GNSS+ 2015, Tampa, Florida, 15-18, September 2015

Leandro, R., et al (2011), RTX Positioning: The Next Generation of cm-accurate Real-time GNSS Positioning, Proc. ION GNSS 2011, Portland, Oregon, 1460-1475.

Li, X., G. Dick, M. Ge, S. Heise, J. Wickert, and M. Bender (2014), Real-time GPS sensing of atmospheric water vapor: Precise point positioning with orbit, clock, and phase delay corrections, Geophys. Res. Lett., 41, 3615-3621, doi:10.1002/2013GL058721.

Li, X., F. Zus, C. Lu, G. Dick, T. Ning, M. Ge, J. Wickert, and H. Schuh (2015a), Retrieving of atmospheric parameters from multi-GNSS in real time: Validation with water vapor radiometer and numerical weather model, J. Geophys. Res., 120(14), 7189-7204, doi:10.1002/2015JD023454.

Li, X., G. Dick, C. Lu, M. Ge, T. Nilsson, T. Ning, J. Wickert, and H. Schuh (2015b), Multi-GNSS meteorology: Real-time retrieving of atmospheric water vapor from BeiDou, Galileo, GLONASS, and GPS observations, IEEE Transactions on Geoscience and Remote Sensing, 99, 1-9, doi:10.1109/TGRS.2015.2438395.

Lu, C., X. Li, T. Nilsson, T. Ning, R. Heinkelmann, M. Ge, S. Glaser, and H. Schuh (2015), Real-time retrieval of precipitable water vapor from GPS and BeiDou observations, J. Geod., 89(9), 843-856, doi:10.1007/s00190-015-0818-0. 
Lyard, F., F. Lefevre, T. Letellier, and O. Francis (2006), Modelling the global ocean tides: A modern insight from FES2004, Ocean Dyn., 56, 394-415, doi:10.1007/s10236-006-0086-x.

Madhulatha, A., M. Rajeevan, M. Venkat Ratnam, J. Bhate, C. V. Naidu (2013), Nowcasting severe convective activity over southeast India using ground-based microwave radiometer observations, J. Geophys. Res., 118(1), 1-13, doi: 10.1029/2012JD018174.

Mass, C. (2012), Nowcasting: The promise of new technologies of communication, modeling, and observation, Bulletin of the American Meteorological Society, 93(6), 797-809, doi:http://dx.doi.org/10.1175/BAMS-D-11-00153.1.

Montenbruck, O., P. Steigenberger, and A. Hauschild (2015), Broadcast versus precise ephemerides: a multi-GNSS perspective, GPS Solut., 19(2), 321-333, doi:10.1007/s10291-014-0390-8.

Niell, A. E., A. J. Coster, F. S. Solheim, V. B. Mendes, P. C. Toor, R. B. Langley, and C. A. Upham (2001), Comparison of measurements of atmospheric wet delay by radiosonde, water vapor radiometer, GPS, and VLBI, J. Atmos. Ocean Technol., 18, 830-850, doi:http://dx.doi.org/10.1175/1520-0426(2001)018<0830:COMOAW>2.0.CO;2.

Ning, T., R. Haas, G. Elgered, and U. Willén (2012), Multi-technique comparisons of 10 years of wet delay estimates on the west coast of Sweden, J. Geod., 86(7), 565-575, doi:10.1007/s00190-011-0527-2.

Pavlis, N. K., S. A. Holmes, S. C. Kenyon, and J. K. Factor (2012), The development and evaluation of the Earth Gravitational Model 2008 (EGM2008), J. Geophys. Res., 117(B4), B04406, doi:10.1029/2011JB008916.

Rizos, C., O. Montenbruck, R. Weber, R. Neilan, and U. Hugentobler (2013), The IGS MGEX Experiment as a Milestone for a Comprehensive Multi-GNSS Service, ION-PNT-2013, Honolulu, 22-25 Apr.

Rocken, C., R. H. Ware, T. Van Hove, F. Solheim, C. Alber, J. Johnson, M. Bevis, and S. Businger (1993), Sensing atmospheric water vapor with the global positioning system, Geophys. Res. Lett., 20(23), 2631-2634, doi:10.1029/93GL02935.

Rocken, C., T. Van Hove, and R. H. Ware (1997), Near real-time GPS sensing of atmospheric water vapor, Geophys. Res. Lett., 24, 3221-3224, doi: 10.1029/97GL03312.

Saastamoinen, J. (1973), Contributions to the theory of atmospheric refraction-part II. Refraction corrections in satellite geodesy, Bull. Geod., 107, 13-24, doi:10.1007/BF02522083.

Schmid, R., P. Steigenberger, G. Gendt, M. Ge, and M. Rothacher (2007), Generation of a consistent absolute phase-center correction model for GPS receiver and satellite antennas, J. Geod., 81(12), 781-798, doi:10.1007/s00190-007-0148-y.

Shi, C., Q. Zhao, Z. Hu, and J. Liu (2013), Precise relative positioning using real tracking data from COMPASS GEO and IGSO satellites, GPS Solut., 17(1), 103-119, doi:10.1007/s10291-012-0264-x. 
Shi, J., Y. Gao (2012), Improvement of PPP-inferred tropospheric estimates by integer ambiguity resolution, Adv. Space Res., 50(10), 1374-1382, doi:10.1016/j.asr.2012.06.036

Tegedor, J., O. Øvstedal, and E. Vigen (2014), Precise orbit determination and point positioning using GPS, GLONASS, Galileo and BeiDou, J. Geod. Sci., 4(1), 65-73, doi:10.2478/jogs-2014-0008.

Teke, K., et al (2011), Multi-technique comparison of troposphere zenith delays and gradients during CONT08, J. Geod., 85, 395-413, doi:10.1007/s00190-010-0434-y.

Urlichich, Y., V. Subbotin, G. Stupak, V. Dvorkin, A. Povalyaev, and S. Karutin (2011), GLONASS modernization, Proc. ION GNSS 2011, Portland, Oregon, September 19-23, 2011, 3125-3128.

Van Baelen, J., J. Aubagnac, and A. Dabas (2005), Comparison of near-real time estimates of integrated water vapor derived with GPS, radiosondes, and microwave radiometer, J. Atmos. Ocean Tech., 22(2), 201-210, doi:http://dx.doi.org/10.1175/JTECH-1697.1.

Vedel, H., X. Y. Huang, J. Haase, M. Ge and E. Calais (2004), Impact of GPS zenith tropospheric delay data on precipitation forecasts in Mediterranean France and Spain, Geophys. Res. Lett., 31(2), L02102, doi:10.1029/2003GL017715.

Yuan, Y., K. Zhang, W. Rohm, S. Choy, R. Norman, and C.S. Wang (2014), Real-time retrieval of precipitable water vapor from GPS precise point positioning, J. Geophys. Res., 119, 10044-10057, doi:10.1002/2014JD021486.

Zumberge, J. F., M. B. Heflin, D. C. Jefferson, M. M. Watkins, and F. H. Webb (1997), Precise point positioning for the efficient and robust analysis of GPS data from large networks, J. Geophys. Res., 102(B3), 5005-5017, doi:10.1029/96JB03860. 